\title{
PRODUCTION OF HYDROGEN PEROXIDE FROM ALUMINUM AND ZINC.
}

BY H. T. BARNES AND G. W. SHEARER

In a paper on "A Hydrogen Peroxide Cell" recently published by us in this Journal," we have described the production of hydrogen peroxide in measurable quantities in pure water, containing clean aluminum metal, in which air or oxygen was dissolved. Keeping the water charged with air by bubbling or shaking causes a marked increase in the yield of peroxide.

At the end of our paper we state that similar experiments for zinc had yielded negative results.

Since this paper was published, however, we have repeated the experiments in a different way and have obtained considerable quantities of the peroxide. The failure of our previous tests was due to using the zinc in a powder and allowing the water to stand too long in contact.

We find that the peroxide is decomposed fairly rapidly by standing with zinc, whereas, with aluminum the peroxide is only slowly decomposed, if at all.

Clean granulated zinc in pure distilled water through which air is passed, develops considerable peroxide, but on standing, the peroxide is all decomposed in from 7 to 8 hours.

The slow action of the aluminum in decomposing the peroxide is probably due to the surface film which forms and protects the metal. In the case of zinc this surface film does not seem to be so protective, the hydroxide being more readily detached. We have tried also, copper, platinum and iron in a similar way, but up to the present have not detected free peroxide in the water. Magnesium metal gives a faint reaction for peroxide, and we believe that it is probable all the metals which show anomalous anodic conductivity are likely to develop free peroxide.

\section{McGill University, \\ May 21, rgo8.}

${ }^{1}$ Jour. Phys. Chem., I2, I55 (Ig08). 